\title{
Dementia among older patients attending National Institute of Mental Health (NIMH), Dhaka, Bangladesh
}

\author{
Arman Ibne Haq, ${ }^{1}$ Mekhala Sarkar, ${ }^{2}$ Susmita Roy, ${ }^{3}$ Md Faruq Alam ${ }^{4}$ \\ ${ }^{1}$ Registrar, Department of Psychiatry, Bangladesh Medical College, Dhaka, Bangladesh; ${ }^{2}$ Assistant Professor, Department of \\ Forensic Psychiatry, National Institute of Mental Health (NIMH), Sher-E-Bangla Nagar, Dhaka, Bangladesh; ${ }^{2}$ Associate Professor, \\ Department of Psychiatry, Jalalabad Ragib Rabeya Medical College, Sylhet, Bangladesh; ${ }^{4}$ Professor, Department of Child, \\ Adolescent and Family Psychiatry, NIMH, Dhaka, Bangladesh.
}

Article info

Received : 02 Dec. 2016

Accepted : 15 Jan. 2017

Number of tables : 06

Number of figures : 05

Number of refs : : 17

\section{Correspondence}

Arman Ibne Haq,

E-mail: armanibnehaq@yahoo.com

\begin{abstract}
Summary
Dementia has become the focus of attention of health care professionals' worldwide. The objective of the study was to find out the proportion of dementia among older patients as well as to identify the socio-demographic characteristics of patients with dementia attending National Institute of Mental Health (NIMH), Sher-E-Bangla Nagar, Dhaka, Bangladesh. This was a cross sectional study conducted in NIMH during the period from $1^{\text {st }}$ November 2014 to $30^{\text {th }}$ April 2015. For this purpose, 78 elderly patients aged e"60 years attending both in outpatient and inpatient departments of $\mathrm{NIMH}$, satisfying inclusion and exclusion criteria were selected by convenient sampling technique. Data were collected by face-to-face interview using semi-structured questionnaire. Cognitive impairment was assessed by Bengali version of Mini Mental State Examination (MMSE) and dementia was diagnosed according to Diagnostic and Statistical Manual for Mental Disorders, 5th edition (DSM-5). The results showed that most of the patients (51.3\%) were in between the ages of 60 to 64 years with male predominance $(56.4 \%)$. The mean ( \pm SD) age of the patients was $66.84( \pm 5.49)$ years. Among the patients $43.6 \%$ came from urban area, $39.7 \%$ from the family with monthly income within 30001-45000 Bangladeshi taka (BDT) and $53.9 \%$ had family members in between 4 to 6 . Among them $61.5 \%$ patients were married, $43.6 \%$ were retired from service, $32.1 \%$ studied up to primary level and $62.8 \%$ had caregivers. Most of them (88.5\%) scored between 24-30 in Mini Mental State Examination (MMSE) and only 5.1\% respondents had dementia. This study has provided baseline information about the proportion of dementia among elderly patients in Bangladesh that can be used in future studies.
\end{abstract}

Bang J Psychiatry 2015;29(1):5-9

\section{Introduction}

The older population is rapidly growing throughout the world. It has been estimated that the elderly will exceed 1 billion by $2020{ }^{1}$ The increasing number of the older people has imposed a huge health impact on the society and is also accompanied by the greater decline in health and different domains of function. ${ }^{2}$ Among the old population dementia has become the focus of attention of health care professionals' worldwide. This chronic progressive neurodegenerative disorder is a major cause of morbidity and mortality in the elderly population. Dementia is a condition which usually starts after the age of 65 years, but it may occur before the age of 65 years. ${ }^{3}$ In Diagnostic and Statistical Manual of Mental Disorders, Fifth Edition (DSM-5) dementia is placed under major neurocognitive disorders where cognitive deficits interfere with independence in everyday activities. ${ }^{4}$ The prevalence of dementia is approximately $5 \%$ in general population older than 65 years of age and $20-40 \%$ in general population older than 85 years. ${ }^{5}$ Different studies in Asia showed the prevalence of dementia among the persons aged 65 years and above were in between $2.4 \%$ to $3.5 \%$. ${ }^{6} 8$
According to World Health Organization (WHO), dementia has emerged as a public health priority because it causes the devastating economic burden on families and nations. The cost of dementia will rise at a greater rate than the prevalence. Therefore, societies all over the world should be prepared to face the social and economic burden of dementia. ${ }^{9}$ Dementia is overwhelming for the caregivers. One study in India found that caregivers of people with dementia spent significantly longer time providing care and 16 times more likely to have a common mental disorder than care givers of other chronic disorders. ${ }^{10}$ With the world's eighth largest population with 160 million people, the percentage of people aged more than 60 years in Bangladesh is projected to increase to $9 \%$ by 2025 and $21 \%$ by $2050 .{ }^{11}$

Considering the above-mentioned facts on the dearth of data on dementia in Bangladesh and its huge importance have impelled the author to undertake the study. The objective of the study was to find out the proportion of dementia among older patients as well as to identify the socio-demographic characteristics of patients with dementia. This study will be a baseline study on dementia. 


\section{Materials and methods}

This cross sectional study was conducted in National Institute of Mental Health (NIMH) at Sher-E-Bangla Nagar, Dhaka, Bangladesh during the period from $1^{\text {st }}$ November 2014 to $30^{\text {th }}$ April 2015. For this purpose, 78 elderly patients aged e"60 years attending in both outpatient and inpatient departments of NIMH were selected by convenient sampling technique. Patients with acute confusional state, acute physical illness and severe visual or hearing impairment were not included in this study. Informed consent was taken from each patient before enrolment in this study. The respondents were interviewed face-to-face using socio demographic questionnaire. Cognitive impairment was assessed by Bengali version of Mini Mental State Examination (MMSE) and dementia was diagnosed according to Diagnostic and Statistical Manual for Mental Disorders, 5th edition (DSM-5). The interviews were held in a peaceful and non-threatening environment. After collecting data, editing was done manually and was analyzed with the help of Statistical Package for the Social Sciences (SPSS) software package version 16. Ethical issues were maintained properly throughout the study.

\section{Results}

Most of the patients (51.3\%) were between the ages of 60 to 64 years with male predominance $(56.4 \%)$. The mean $( \pm S D)$ age of the patients was calculated as $66.84( \pm 5.49)$ years. Majority of the respondents (93.6\%) were Muslims, $43.6 \%$ came from urban area, $39.7 \%$ from the family with monthly income within $30001-45000$ BDT and $61.5 \%$ were married (Table 1).

Table 1: Distribution of respondents according to socio demographic characteristics $(n=78)$

\begin{tabular}{lcc}
\hline Socio demographic characteristics & Frequency & $\%$ \\
\hline Age group (in years) & & \\
$60-64$ & 40 & 51.3 \\
$65-69$ & 21 & 26.9 \\
$70-74$ & 10 & 12.8 \\
$75-79$ & 05 & 6.4 \\
$80-84$ & 02 & 2.6 \\
Mean: 66.84 years, Median: 65.00 years, Mode: 62 years \\
Sex & & \\
Male & 44 & 56.4 \\
Female & 34 & 43.6 \\
Religion & & \\
Islam & 73 & 93.6 \\
Hindu & 5 & 6.4 \\
Habitat & & \\
Urban & 34 & 43.6 \\
Semi-urban & 16 & 20.5 \\
Rural & 28 & 35.9 \\
Marital Status & & \\
Married & 48 & 61.5 \\
Widower & 30 & 38.5 \\
Monthly income (in BDT) & & \\
S15000 & 13 & 16.7 \\
15001-30000 & 28 & 35.9 \\
30001-45000 & 31 & 39.7 \\
>45001 & 6 & 7.7 \\
\hline
\end{tabular}

Mean:36961.54 BDT, Median:25000 BDT, Mode:25000 BDT
Among the respondents $43.6 \%$ were retired from service, $29.5 \%$ were housewives, $16.7 \%$ were farmers and $10.2 \%$ were doing some sort of business (Figure 1). About $32 \%$ of the respondents studied up to primary level. Among the rest, $18.0 \%$ educated up to the secondary level, $18.0 \%$ were graduate and $14.1 \%$ studied up to higher secondary level (Figure 2).

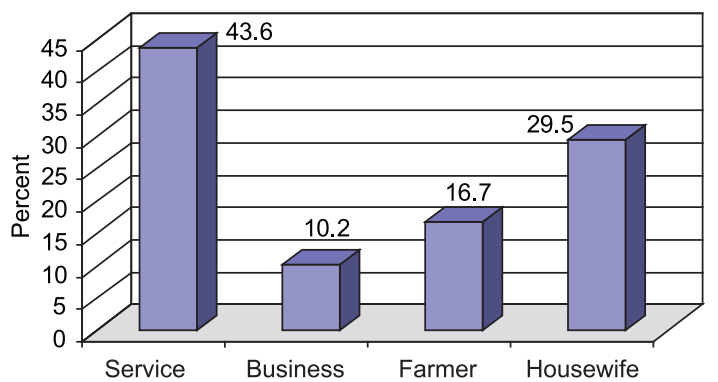

Figure 1: Occupational status of the respondents $(n=78)$

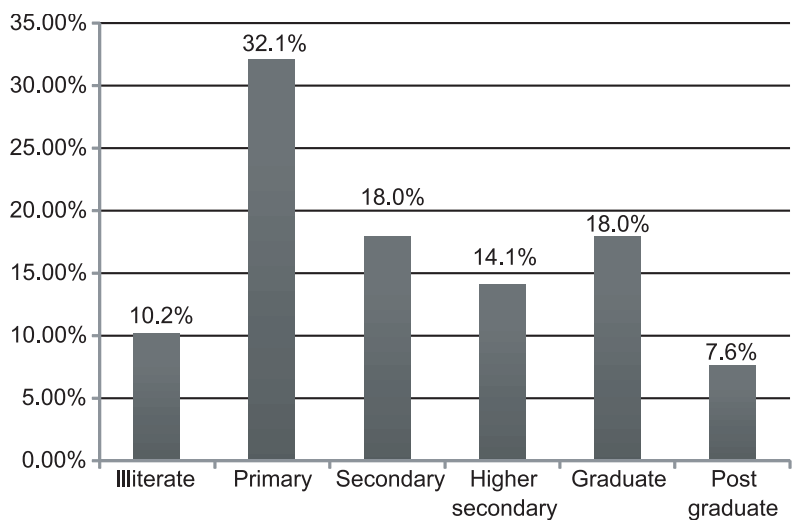

Figure 2: Educational level of the respondents $(n=78)$

More than half of the respondents, $53.9 \%$ had family members in between 4 to 6 (Table 2). Sons or daughters of half (50\%) of respondents, were the guardian of the families and in $43.6 \%$ either husbands or wives were the guardian (Figure 3). Among all respondents $49(62.8 \%)$ had caregivers (Figure 4). Most $(91.8 \%)$ of the care givers were without pay whereas $85.7 \%$ unpaid care givers were the female members of the families and only $8.2 \%$ were paid (Table 3 ).

Table 2: Distribution of respondents according to number of family member $(n=78)$

\begin{tabular}{lcc}
\hline Number of family members & Frequency & $\%$ \\
\hline $1-3$ & 15 & 19.2 \\
$4-6$ & 42 & 53.9 \\
$7-10$ & 16 & 20.5 \\
Â10 & 5 & 6.4 \\
\hline
\end{tabular}

Mean: 5.6, Median: 5, Mode: 6 


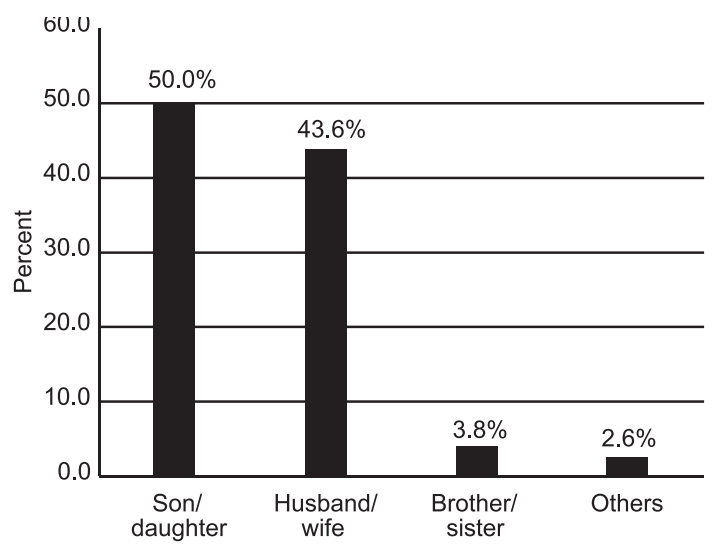

Figure 3: Pattern of guardians of the family $(n=78)$

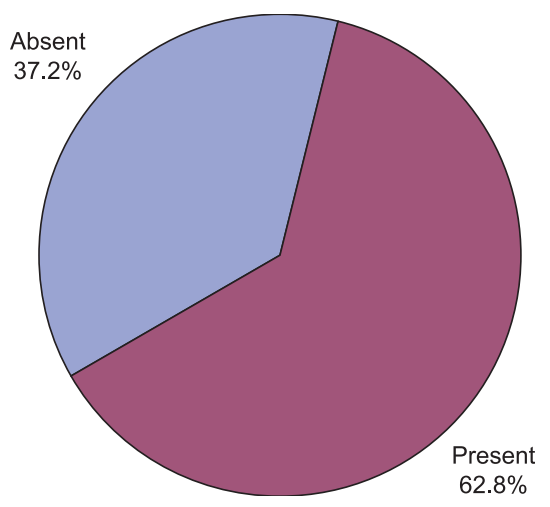

Figure 4: Presence of care giver $(n=78)$

Table 3: Distribution of care givers of respondents $(n=49)$

\begin{tabular}{|c|c|c|c|}
\hline $\begin{array}{l}\text { Types of } \\
\text { care giver }\end{array}$ & Relation with respondent & Frequency & $\%$ \\
\hline \multirow[t]{2}{*}{ Without pay } & $\begin{array}{l}\text { Wife, Daughter, } \\
\text { Daughter-in-law }\end{array}$ & 42 & 85.7 \\
\hline & $\begin{array}{l}\text { Husband, Son, } \\
\text { Son-in-law }\end{array}$ & 3 & 6.1 \\
\hline With pay & $\begin{array}{l}\text { House hold } \\
\text { Worker }\end{array}$ & 4 & 8.2 \\
\hline
\end{tabular}

Majority (88.5\%) of the patients scored between 24-30 in MMSE while only $9(11.5 \%)$ respondents scored d"23 (Table 4). Among the respondents who scored d"23, only $4(5.1 \%)$ had dementia according to DSM 5 and the mean MMSE score was 15.25 (Table 5).

Table 4: Distribution of respondents according to MMSE score $(n=78)$

\begin{tabular}{lcc}
\hline MMSE score & Frequency & $\%$ \\
\hline $24-30$ & 69 & 88.5 \\
$23-18$ & 7 & 8.9 \\
$\leq 17$ & 2 & 2.6 \\
\hline
\end{tabular}

Table 5 : Mean MMSE score and proportion of dementia $(n=9)$

\begin{tabular}{lcc}
\hline Characteristics & Dementia present & Dementia absent \\
\hline Number & 4 & 5 \\
Mean MMSE score & 15.25 & 22.4 \\
SD & 5.68 & 0.55 \\
\hline
\end{tabular}

Of the four respondents diagnosed with dementia, one (25\%) was less than 65 years of age and three $(75 \%)$ were more than 65 years old $\left(c^{2}=1.1657, p=0.28029\right)$. Two $(50 \%)$ demented patients were male and two $(50 \%)$ were female $\left(c^{2}=0.0705\right.$, $\mathrm{P}=0.79067)$. Three $(75 \%)$ of the respondents diagnosed with dementia were widow or widowers and one was married $\left(\mathrm{c}^{2}=\right.$ $2.3782, P=0.12304)$. Majority $(75 \%)$ of dementia patients were educated less than higher secondary level and only one (25\%) was more than higher secondary level $\left(c^{2}=0.3827, P=0.53616\right)$. Family income of two (50\%) of the demented patients were less than 30,000 BDT and two had family income of more than 30,000 $\operatorname{BDT}\left(c^{2}=0.0111, P=0.91603\right)$ (Table 6).

Table 6: Socio-demographic factors and dementia $(n=78)$

\begin{tabular}{|c|c|c|c|}
\hline Variables & $\begin{array}{l}\text { No dementia } \\
\quad(n=74)\end{array}$ & $\begin{array}{c}\text { Dementia } \\
(n=4)\end{array}$ & Pvalue \\
\hline \multicolumn{4}{|l|}{ Age } \\
\hline$<65$ years & $39(52.7 \%)$ & $1(25 \%)$ & $c^{2}=1.1657$ \\
\hline$\geq \mathrm{H} 65$ years & $35(47.3 \%)$ & $3(75 \%)$ & $P=0.28029$ \\
\hline \multicolumn{4}{|l|}{ Sex } \\
\hline Male & $42(56.8 \%)$ & $2(50 \%)$ & $2=0.0705$ \\
\hline Female & $32(43.2 \%)$ & $2(50 \%)$ & $P=0.79067$ \\
\hline \multicolumn{4}{|l|}{ Marital status } \\
\hline Married & $47(63.5 \%)$ & $1(25 \%)$ & $c^{2}=2.3782$ \\
\hline Widow/widowers & $27(36.5 \%)$ & $3(75 \%)$ & $P=0.12304$ \\
\hline \multicolumn{4}{|l|}{ Education } \\
\hline$<$ <igher & $44(59.5 \%)$ & $3(75 \%)$ & $c^{2}=0.3827$ \\
\hline secondary & $30(40.5 \%)$ & $1(25 \%)$ & $P=0.53616$ \\
\hline \multicolumn{4}{|l|}{$\geq$ Hhigher secondary } \\
\hline \multicolumn{4}{|l|}{ Family income } \\
\hline$<30,001 \mathrm{BDT}$ & $39(52.7 \%)$ & $2(50 \%)$ & $2=0.0111$ \\
\hline$\geq 30,001 \mathrm{BDT}$ & $35(47.3 \%)$ & $2(50 \%)$ & $P=0.91603$ \\
\hline
\end{tabular}

\section{Discussion}

The present study showed that the proportion of dementia in the elderly respondents was $5.1 \%$. A community based survey in Pune, India yielded a prevalence rate $4.1 \% .{ }^{12} \mathrm{~A}$ study in a rural community in Kerala showed a prevalence of 33.9 per 1000 in people aged 60 years and above. ${ }^{13}$ Compared to this study, a western study showed a higher prevalence rate $(9.8 \%) .{ }^{14}$ Prevalence of dementia varied from one study to another depending on the geographical area and the demographic profile of the study population. Studies done in the developed world showed a higher rate of prevalence due to longer life expectancy resulting in higher percentage of elderly in the population. In addition, the prevalence of dementia may vary between hospital 
and community based studies. The mean (+ SD) age of the respondents was calculated as $66.84 \pm 5.49$ years. Minimum age was 60 years and maximum age was 83 years. More than half $(51.3 \%)$ of the respondents were between $60-64$ years. Of the respondents $(n=4)$ diagnosed with dementia, three $(75 \%)$ were more than 65 years old. A large number of studies have found that increasing age as the most consistent risk factor for dementia. A study in Malaysia showed majority of the respondents (66.2\%) was from age group 65-74 years. The youngest was 65 years old and the eldest was 92 years old. Mean (+ SD) age of the respondents was 72.95 (72.95 \pm 4.91)years. ${ }^{9}$ This was probably due to the fact that the average life expectancy in Bangladesh is 70.7 years in contrast to 74.1 years in Malaysia. A hospital based study in India showed $92.85 \%$ of the patients were in the age range of 60-69 years, in the 7079 years age range in there were $5.95 \%$ cases and in the 80 years and above category, there was only $1.19 \%$ case. ${ }^{15}$ The higher distribution of respondents in this study within the 70-84 age groups was due to higher average life expectancy in Bangladesh (70.7 years) compared to India (66.4 years).

Proportion of male and female respondents in this study was $56.4 \%$ and $43.6 \%$ respectively. Male to female ratio was 1.29:1. Proportion of dementia in the male respondents was $4.5 \%$ and in female respondents $5.9 \%$. A study conducted in the outpatient department of a Malaysian hospital showed male respondents were $50.6 \%$ and female respondents were $49.4 \%$ and proportion of dementia among the two sexes were $1.0 \%$ and $4.23 \%$ respectively. ${ }^{7}$ The average life expectancy of females is higher than males. However, this fact was not reflected in the hospitalbased studies in Asia. Several reasons may be responsible for this fact like gender disparity, lack of awareness among the females, less willingness on the part of females to come forward with their problems, greater dependence than their male counterparts may on other family members.

Most (93.6\%) of the study respondents were followers of Islam followed by Hindu (6.4\%). In a study conducted in Kerala, $47.8 \%$ respondents were followers of $\mathrm{Hindu}, 45.2 \%$ Christian and $7.0 \%$ were Muslim ${ }^{16}$ which was not consistent with this study as Bangladesh is a Muslim predominant country. In this study educational status of the respondents were $10.2 \%$ illiterate, $32.1 \%$ primary, $18.0 \%$ secondary, $14.1 \%$ higher secondary, $18.0 \%$ graduate and $7.6 \%$ were post graduate. Three $(75 \%)$ of the respondents diagnosed with dementia were educated less than higher secondary level and only one (25\%) was more than higher secondary level. Astudy done in Kerala, India found educational level among the respondents were Illiterate $11.2 \%$, primary $44.0 \%$, secondary $27.9 \%$, higher secondary $6.9 \%$, graduate $5.7 \%$, postgraduate $4.3 \% .{ }^{16}$ The higher percentage of graduates and post graduates in this study can be explained by the fact that a large portion of the respondents lived in an urban area. It has been shown that higher level of formal education enhances the cognitive reserve and acts as a protective factor against the development of dementia. This study was conducted in a tertiary level hospital situated in Dhaka city. As a result, a major (43.6\%) portion of the respondents came from urban area. Primary health care workers referred rural patients who constituted second largest (35.9\%) portion of the respondents to this institute. Rest $(20.5 \%)$ came from semi urban areas surrounding Dhaka city. Elderly people aged more than 60 years were the respondents of this study. As a result, large portions (38.5\%) of the respondents were widows or widowers and about half of them were retired. Three of the older persons with dementia were either widows or widowers and only one was married. In accordance with the tradition of our country, more than half $(53.9 \%)$ of the elderly respondents had family member in between 4-6 persons.

Majority (62.8\%) of the elderly respondents in this study had caregiver. Most (91.8\%) of the care givers were without pay where as $85.7 \%$ of the unpaid care givers were female members of the families and only $8.2 \%$ were paid. All of the paid caregivers were household workers. All of the four dementia patients had unpaid caregivers who were female member of the family. In a qualitative study of 17 caregivers of people with Alzheimer's disease in India showed that the majority of caregivers were young women, often daughters-in-law. ${ }^{17}$ In developing countries most of the care givers are female member of the family as adult males of the family are the income source and appointing a paid care giver can put an enormous financial strain on the family. As majority of the elderly respondents were retired, they depended on the earnings of other family members. The role of guardian of the family was played by either son or daughter in half (50\%) of the cases and in $43.6 \%$ case respondent themselves or their spouse acted as the guardian. Nine out of the total respondents scored below 24 in the MMSE. Four of these nine respondents were clinically diagnosed as dementia. Those who had dementia had lower MMSE score than those who did not (mean score 15.25 vs. 22.4).

\section{Conclusion}

This study provided baseline information about proportion of dementia among elderly patients in Bangladesh. The findings used to be addressed carefully need evaluation extensively before drawing any conclusion because it was a hospital based study. The findings can be used in future studies yet the researchers should view the findings provisional and approximate.

\section{References}

1. World Health Organization. Population ageing: a looming public health challenge. Geneva: World Health Organization; 1998. 
2. Zhu L, Fratiglioni L, Guo Z, Aguero-Torres H, Winblad B, Viitanen M. Association of stroke with dementia, cognitive impairment, and functional disability in the very old: a population-based study. Stroke 1998;29(10):2094-9.

3. Larson EB, Yaffe K, Langa KM. New insights into the dementia epidemic. New Eng J Med 2013;369:2275-7.

4. American Psychiatric Association. Diagnostic and Statistical Manual of Mental Disorders. $5^{\text {th }}$ Ed. Arlington VA: American Psychiatric Press; 2013.

5. Sadock BJ, Sadock VA eds. Kaplan and Sadock's Synopsis of psychiatry, $10^{\text {th }}$ ed. Philadelphia: Lippincott, Williams and Wilkins; 2007. p. 329-44.

6. Wang W, Wu S, Cheng X, Dai H, Ross K, Du X, et al. Prevalence of Alzheimer's disease and other dementing disorders in an urban community of Beijing, China. Neuroepidemiology 2000;19(4):194-200.

7. Norlaily H, Azidah AK, Asrenee AR, Rohaya H, Juwita S. Proportion of Dementia and its associated factors among elderly patients attending outpatient clinics of Universiti Sains Malaysia Hospital. Med J Malaysia 2009;64(2):140-5.

8. Vas CJ, Pinto C, Panikker D, Noronha S, Deshpande N, Kulkarni L, et al. Prevalence of dementia in an urban Indian population. Int Psychogeriatr 2001;13(4):439-50.

9. Catriona D, McCullagh C, Craig D, Mcilroy SP, Passmore AP. Risk factors for dementia. Adv psychiatr treat 2001;7:24-31.
10. Alzheimer Society of Bangladesh. Dementia statistics. Dhaka: Alzheimer Society of Bangladesh; 2013.

11. Das A, Samuel R, Patel V, Prince M, Parameshwaran R, Krishnamoorthy ES. The impact associated with caring for a person with dementia: a report from the 10/66 dementia research group's Indian network. Int J Geriatr Psychiatry 2004;19:182-4.

12. Saldanha D, Mani R, Srivastava K, Goyal S, Bhattacharya D. An epidemiological study of dementia under the aegis of mental health program, Maharashtra, Pune chapter. Indian J Psychiatry 2010;52(2):131-9.

13. Shaji S, Promudu K, Abraham T, Roy KJ, Verghese A. An epidemiological study of dementia in a rural community in Kerala, India. Br J Psychiatry 1996;168(6);745-9.

14. Lobo A, Dewey M, Copeland J, Día JL, Saz P. The prevalence of dementia among elderly people living in Zaragoza and Liverpool. Psychol Med 1992;22(1):239-43.

15. Ferini-Strambi L, Marcone A, Garancl P, Danelon F, Zamboni $M$, Massussi $P$, et al. Dementing disorder in North Italy: prevalence study in Viscovata, Cremona Province. Eur J Epidemiol 1997;13:201-4.

16. Shaji S, Bose S, Verghese A. Prevalence of dementia in an urban population in Kerala, India. $\mathrm{Br} \mathrm{J}$ Psychiatry 2005;186:136-40.

17. Tiple P, Sharma SN, Srivastava AS. Psychiatric morbidity in geriatric people. Indian J Psychiatry 2006;48(2):88-94. 